\title{
Increased resting energy expenditure in childhood asthma: does this contribute towards growth failure?
}

\author{
S R Zeitlin, S Bond, S Wootton, R K Gregson, M Radford
}

\begin{abstract}
In order to determine whether or not there was a relationship between disorders of growth in children suffering from asthma and either increased resting energy expenditure or inadequate energy intake, a group of 34 children suffering from perennial symptoms were studied. A control group matched with the asthmatic children for sex and fat free mass were similarly studied.

The children kept seven day records of weighed food intake. Basal metabolic rate was measured on one occasion in the fasted state by means of indirect calorimetry using the ventilated hood technique. The asthmatic children kept a 28 day record of peak expiratory flow rates, asthma symptoms, and medication usage.

The asthmatic children expended significantly more energy at rest than their matched controls in absolute terms (14\%). There was no correlation between height or height SD score and any parameter of energy balance. The causes of these finding are as yet speculative.
\end{abstract}

\section{(Arch Dis Child 1992;67:1366-9)}

The interaction of the disease process, drug treatment, and energy expenditure and their effect on growth in chronic disease states, such as asthma, are poorly understood. While an association between asthma and short stature is well recognised, ${ }^{12}$ the factors that contribute towards poor growth and the incidence of the problem are less well documented. ${ }^{34}$

Since Cohen et al first described growth disorders in asthmatic children in $1940^{1}$ attempts to quantify and explain the problem have been confounded by a number of obstacles. The definition of asthma and hence its incidence has changed considerably over the last 20 years. $^{5}$ The term 'asthma' now encompasses a much broader spectrum of disease. ${ }^{67}$

Growth is the end result of a number of physiological pathways. Simplistically a reduction in the rate of growth is a consequence of an imbalance between energy intake and energy expenditure. Three factors must be considered: dietary intake, abnormal excretory losses, and the nature and magnitude of metabolic demands. Such imbalances may be small and accrue over prolonged periods of ill health or result from repeated periods of acute exacerbations of disease. Deficiencies of specific micronutrients that may also limit growth once energy needs are satisfied should not be overlooked. ${ }^{8}$ There have been no studies in which both intake and expenditure of energy have been determined in children with asthma.

The purpose of this study was to examine the extent to which poor growth in asthmatic children could be attributed to poor energy intake or an increased metabolic demand for energy. Measurements of energy intake and basal metabolic rate (BMR) were made for children suffering from chronic perennial asthma of comparable severity between acute exacerbations of their asthma. Their results were compared with those from normal healthy children matched for sex and fat free mass.

\section{Patients and methods}

This study was conducted with the approval of the Southampton and South West Hampshire Health Authority ethical committee and informed consent was obtained from the parents of all of the children that took part.

Thirty four children ( 25 boys, nine girls) aged $6 \cdot 8-12 \cdot 7$ years (mean $8 \cdot 6$ years) suffering from chronic perennial asthma were recruited from the paediatric outpatient clinic at Southampton General Hospital. All of the children were graded as Tanner score 1 for sexual maturity on physical examination. ${ }^{9}$ Each of the asthmatic children kept a diary in which they recorded their use of medication and measurements of peak flow for a period of 28 days. Peak expiratory flow rate (PEFR) was determined as the best of three attempts at peak flow measurements on rising in the morning before administration of inhaled bronchodilators and again before retiring. From this the number of days when the PEFR was less than $75 \%$ of the predicted value for that child and the days when the diurnal variation exceeded $25 \%$ of the predicted PEFR were calculated. Thirty four healthy prepubertal children recruited from local schools were matched with the study children for sex and fat free mass. None of the control group suffered from asthma. The control subjects were aged 5.39-11.78 years (mean 8.67 years).

Weighed dietary intake was recorded for a period of seven days in the standard manner described by Marr, ${ }^{10}$ using digital electronic scales (Hanson). The children and their families were instructed in the use of the scales and how to record their food and drink consumption in a notebook provided. The dietary record was checked during a follow up interview with the dietitian. These were then coded according to the McCance and Widdowson food tables. ${ }^{11}$ Using a computerised database (Microdiet), analysis was carried out to determine the 
estimated metabolisable energy intake over the seven day period. Energy intakes were expressed in absolute units, corrected for differences in fat free mass, and in relation to that recommended by the Department of Health and Social Security. ${ }^{12}$

In this study, energy expenditure at rest or BMR was defined as the minimum energy expenditure for maintaining essential bodily functions under standardised resting conditions, 12-18 hours postprandial. All measurements were performed between 0730 and 1030, after an overnight fast. BMR was determined by indirect calorimetry using an open circuit ventilated hood system. Oxygen consumption and respiratory exchange ratio were measured to calculate BMR. ${ }^{13}$ During the measurement the subjects lay supine on a bed listening to music or story tapes. Room temperature was maintained at $22-24^{\circ} \mathrm{C}$. The measurements were conducted for a minimum period of $\mathbf{3 0}$ minutes after a stable energy expenditure was achieved.

All of the asthmatic children received inhaled bronchodilator on the morning of the study via the route and in the dose to which they were accustomed. Those normally taking inhaled steroids took their usual dose. None of the children were taking oral theophylline. All of the asthmatics were subjectively well on the day of calorimetry.

BMR was expressed in $\mathrm{kJ}$ per 24 hours,

Table 1 PEFR and steroid dose in asthmatic children $(n=34)$

\begin{tabular}{llc}
\hline & $\begin{array}{l}\text { No steroids } \\
(n=10)\end{array}$ & $\begin{array}{l}\text { Steroids } \\
(n=24)\end{array}$ \\
\hline PEFR <75\% predicted value & $15(0-28)$ & $2(0-25)$ \\
$\begin{array}{c}\text { (days/28 days) } \\
\text { Morning dip in PEFR }>25 \% \\
\text { of predicted value } \\
\text { (days/28 days) }\end{array}$ & $0(0-2)$ & $0(0-4)$ \\
$\begin{array}{l}\text { Steroid dose ( } \mu \text { g/day } \\
\text { beclomethasone dipropionate) }\end{array}$ & - & $400(100-200)$ \\
\hline
\end{tabular}

corrected for differences in fat free mass, and as a percentage of that predicted on the basis of age, gender, weight, and height. ${ }^{14}$

Height was determined using a Holtain stadiometer and the height SD score ${ }^{15}$ and the predicted height allowing for mean parental height were determined. ${ }^{16}$ Weight was determined by standing balance scales. Fat free mass was determined from skinfold thickness (biceps, triceps, subscapular, and suprailiac sites) measured using Harpenden skinfold callipers and used to determine body density, body fat, and fat free mass. ${ }^{17} 18$

The results were analysed using nonparametric statistics. Values given are median and ranges. Differences between the asthmatic children and their matched controls were analysed using the Wilcoxon matched pairs test. Differences within the asthmatic group were analysed with the Mann-Whitney test.

\section{Results}

Of the 34 asthmatic children who entered the trial, 24 were taking regular inhaled beclomethasone dipropionate for at least three months. The mean (SD) dose of steroid was $341 \cdot 8(322 \cdot 0) \mu \mathrm{g} / 24$ hours. Only one child was receiving regular oral steroids (prednisolone $2 \cdot 5$ mg on alternate days). All of the children took inhaled salbutamol. None of them was taking oral theophylline.

There was no significant difference in the number of days on which the children were assessed as having appreciable reduction in PEFR between the children on inhaled steroids and those that were not (see table 1).

The anthropomorphic characteristics of the asthmatics and the controls are shown in table 2. There was no statistically significant differences between the asthmatics and controls in age, although the asthmatic children were significantly shorter $(p<0.05)$, were lighter

Table 2 Characteristics of asthmatic and control children; values are median (range)

\begin{tabular}{|c|c|c|c|c|}
\hline & \multirow{2}{*}{$\begin{array}{l}\text { Controls } \\
(n=34)\end{array}$} & \multirow{2}{*}{$\begin{array}{l}\text { Total } \\
\text { asthmatics } \\
(n=34)\end{array}$} & \multicolumn{2}{|l|}{ Asthmatics } \\
\hline & & & $\begin{array}{l}\text { No steroids } \\
(n=10)\end{array}$ & $\begin{array}{l}\text { Steroids } \\
(n=24)\end{array}$ \\
\hline $\begin{array}{l}\text { Age (years) } \\
\text { Weight (kg) } \\
\text { Height (cm) } \\
\text { Height SD score } \\
\% \text { Body fat } \\
\text { Fat free mass }(\mathbf{k g})\end{array}$ & $\begin{array}{c}8 \cdot 5(5 \cdot 4-11 \cdot 8) \\
27 \cdot 5(20 \cdot 5-39 \cdot 0) \\
132 \cdot 0(110 \cdot 0-147 \cdot 7) \\
0 \cdot 38(-1 \cdot 52 \text { to } 2 \cdot 13) \\
17 \cdot 0(6 \cdot 6-32 \cdot 9) \\
23 \cdot 0(17 \cdot 3-31 \cdot 7)\end{array}$ & $\begin{array}{l}8 \cdot 3(6 \cdot 7-12 \cdot 7) \\
26 \cdot 0(17 \cdot 5-38 \cdot 4)^{* *} \\
127 \cdot 0(110 \cdot 0-153 \cdot 0)^{*} \\
-0 \cdot 47(-2 \cdot 05 \text { to } 2 \cdot 33) \\
12 \cdot 7(6 \cdot 3-28 \cdot 2)^{* * *} \\
23 \cdot 0(17 \cdot 4-31 \cdot 0)\end{array}$ & $\begin{aligned} & 8 \cdot 9(6 \cdot 8-10 \cdot 8) \\
& 27 \cdot 7(22 \cdot 0-36 \cdot 4) \\
& 131 \cdot 0(123 \cdot 0-153 \cdot 0) \\
& 0 \cdot 26(-0 \cdot 10 \text { to } 1 \cdot 04) \\
& 13 \cdot 6(10 \cdot 2-24 \cdot 5) \\
& 23.9(19 \cdot 1-31 \cdot 0)\end{aligned}$ & $\begin{aligned} & 8 \cdot 1(6 \cdot 7-12 \cdot 7) \\
& 24 \cdot 3(17 \cdot 5-38 \cdot 4) \\
& 125 \cdot 2(110 \cdot 8-140 \cdot 7) \dagger \\
&-0 \cdot 67(-2 \cdot 00 \text { to } 2 \cdot 30) \\
& 10 \cdot 7(6 \cdot 3-28 \cdot 3) \\
& 22 \cdot 3(17 \cdot 4-28 \cdot 2)\end{aligned}$ \\
\hline
\end{tabular}

${ }^{*} \mathrm{p}<0.05 ;{ }^{* *} \mathrm{p}<0.01$, significantly different from controls; $\mathrm{tp}<0.05$, significantly different from no steroids.

Table 3 Energy intake and BMR of asthmatic and control children, values are median (range)

\begin{tabular}{|c|c|c|c|c|}
\hline & \multirow{2}{*}{$\begin{array}{l}\text { Controls } \\
(n=34)\end{array}$} & \multirow{2}{*}{$\begin{array}{l}\text { Total } \\
\text { asthmatics } \\
(n=34)\end{array}$} & \multicolumn{2}{|l|}{ Asthmatics } \\
\hline & & & $\begin{array}{l}\text { No steroids } \\
(n=10)\end{array}$ & $\begin{array}{l}\text { Steroids } \\
(n=24)\end{array}$ \\
\hline \multirow{2}{*}{$\begin{array}{l}\text { Engery intake: } \\
\text { MJ/day } \\
\mathrm{kJ} / \mathrm{kg} \text { fat } \\
\text { free mass/day } \\
\text { Intake:BMR ratio }\end{array}$} & $7 \cdot 41(5 \cdot 19-11 \cdot 22)$ & $8 \cdot 28(427-14 \cdot 88)$ & $8 \cdot 25(5.91-10 \cdot 00)$ & $8 \cdot 29(4 \cdot 27-14 \cdot 88)$ \\
\hline & $\begin{array}{l}340(224-415) \\
1.62(1 \cdot 10-2 \cdot 60)\end{array}$ & $\begin{array}{l}352(188-541) \\
\quad 1.60(0 \cdot 90-2 \cdot 40)\end{array}$ & $\begin{array}{l}328(253-523) \\
1.60(1 \cdot 15-1 \cdot 90)\end{array}$ & $\begin{array}{l}368(188-541) \\
1.60(0 \cdot 91-2 \cdot 40)\end{array}$ \\
\hline \multirow{2}{*}{$\begin{array}{l}\text { BMR: } \\
\text { MJ/day } \\
\text { kJ/kg fat } \\
\text { free mass/day } \\
\text { \%Predicted BMR }\end{array}$} & $4.56(3.48-6.07)$ & $5 \cdot 21(3 \cdot 50-6 \cdot 36)^{*: *}$ & $5 \cdot 26(4 \cdot 76-6 \cdot 14)$ & $4 \cdot 86(3 \cdot 50-6 \cdot 36)$ \\
\hline & $\begin{array}{l}206(130-266) \\
104(65-126)\end{array}$ & $\begin{array}{l}221(186-279)^{* * *} \\
110(70-127)^{* *}\end{array}$ & $\begin{array}{l}218(186-277) \\
110(100-130)\end{array}$ & $\begin{array}{l}225(188-279) \\
110(70-130)\end{array}$ \\
\hline
\end{tabular}

${ }^{*} \mathrm{p}<0.05,{ }^{* *} \mathrm{p}<0 \cdot 01$, significantly different from controls. 
$(p<0.01)$, and exhibited a lower percentage body fat $(p<0.01)$.

The mean BMR of the asthmatic group was significantly greater than controls when expressed in absolute units $(14 \%, \mathrm{p}<0.01)$, relative to fat free mass $(11 \%, p<0.01)$ or as a percentage of the BMR predicted ${ }^{14}$ from age, sex , and weight $(11 \%, p<0.01$; see table 3$)$.

Although there was a trend to higher energy intakes both in absolute terms and per $\mathrm{kg}$ fat free mass, this difference did not attain statistical significance.

The mean (SD) energy intake expressed as a ratio of $B M R$ was $1.65(0.34)$ and $1.68(0.37)$ for the asthmatic and control groups respectively. Further analysis revealed that these results were not influenced by steroid usage.

Six of the asthmatic children were noted to have eczema at the time of the study. These children were found to be either less than the 25 th centile for height or growing at a height growth velocity of less than the 25 th centile for the year before entry into the study. None of the control children had eczema or a history of the disorder.

\section{Discussion}

Over the last 30 years many authors have suggested a link between poor growth and childhood asthma. ${ }^{-419} 20$ Such a link is an appealing concept as many of the chronic diseases of childhood are associated with short stature. ${ }^{21}$ In the asthmatic child however it is not easy to postulate a mechanism for this association. The use of steroids has not been uniformly incriminated. ${ }^{22}{ }^{23}$ There is no evidence of chronic malabsorption in the majority of children and the possibility of a fundamental disorder of growth has not been substantiated.

A distinctive pattern of height growth has however been described. ${ }^{4}{ }^{20}$ Asthmatic children appear to grow at a slightly slower rate initially. They fail to experience the acceleration in growth velocity at the same time as their nonasthmatic peers and they have delayed bone ages. Their adolescent growth spurt tends to be delayed as does the onset of sexual maturation but most children will eventually attain their predicted adult height.

One study that explored the possibility of dietary inadequacy in asthma failed to show a reduced energy intake in short asthmatics and energy supplementation failed to improve their rate of growth. ${ }^{24}$ The role of energy loss in allergic disease is as yet only partially understood.

Increased energy expenditure may occur during attacks of asthma when there is a dramatic increase in the energy cost of breathing. ${ }^{25} 26$ If medication such as inhaled steroids reduced the frequency of exacerbations, it is reasonable to postulate that this might have a benefical effect on overall energy expenditure. The superimposed effects of steroids on linear growth makes this a rather difficult hypothesis to test.

This study represents the first occasion in which energy intakes and basal metabolic rates have been determined in children with chronic asthma. The results suggest that the asthmatic children receiving conventional inhaled treatment have a slightly greater metabolic demand for energy at rest. The raised BMR may be attributable to one or more of several factors. The metabolic demand for energy may be increased by the inflammatory response associated with asthma. ${ }^{27} \mathrm{It}$ is noteworthy that eight of the smallest children had mild eczema. The degree of eczema was unlikely to cause significant protein or fluid loss but might represent a further increase in inflammatory response with a potential increase in metabolic rate. Little information is as yet available about the effect of skin disease on BMR. Food allergies and consequent malabsorption in asthmatics does not appear to be a clinically significant problem in most children. Energy used in the work of breathing may be increased. ${ }^{4}$ Finally, the medication used in an attempt to control the disease may result in alterations in energy expenditure. Vaisman and coworkers have shown that after a single dose of salbutamol a variety of systemic effects may be evident for periods of 3-4 hours. ${ }^{28}$ Energy expenditure at rest increased by $10 \%$ over the first hour after salbutamol inhalation and remained raised for up to 90 minutes. They suggest that such drug related changes in energy expenditure may be important in patients receiving long term bronchodilator treatment. This drug related effect would however account for only a small proportion of the increase in BMR observed in this study.

The increase in BMR in the asthma group was associated with a comparable increase in energy intake of approximately $11 \%$, such that the energy intake:BMR ratios were of the same magnitude. This observation would add further support to the view that the metabolic demand for energy was increased in chronic asthma. It was not possible to demonstrate a relationship between elevated BMR, or low energy intake: $B M R$ ratios and the magnitude of a growth deficit. A single estimate of growth and energy balance using the approaches adopted in this study would be unlikely to be sufficiently sensitive to detect such a direct causal relationship. Furthermore, any increases in BMR may well be compensated for by reductions in the energy expended in physical activity. Expansion of this study to determine long term energy expenditure would help to ellucidate the relationship between expenditure and intake. Recently refined techniques allowing determination of BMR during exercise might add very useful information to the understanding of energy utilisation during activity in asthmatic children. Even if the energy cost of activity were increased, a reduction in the amount of physical activity through breathlessness or anxiety would reduce the amount of energy expended in physical activity.

The results of this study do suggest, however, that the disease process and long term bronchodilator treatment may adversely affect energy balance in patients with chronic lung disease such as asthma. Further studies are required to further explore the extent to which alterations in energy expenditure may contribute towards poor growth in children with asthma. 
Funding for this study was generously provided by Glaxo.

1 Cohen M, Weller R, Cohen S. Anthropometetry in children Progress in allergic children as shown by increments in height weight and maturity. Am $\mathcal{f}$ Dis Child 1940;60: 1058-66.

2 Snyder RD, Collip PJ, Greene JS. Growth and ultimate height in children with asthma. Clin Pediatr (Phila) 1967;6: $389-92$.

3 Fergerson AC, Murray AB, Wah-Tun T. Short stature and skeletal maturation in children with allergic disease. $\mathcal{F ~ C l i n}$ Immunol 1982;69:461-6.

4 Hauspie R, Susanne C, Alexander F. Maturational delay and temporal growth retardation in asthmatic boys. $\mathcal{f}$ Allergy Clin Immunol 1977;59:220-6.

Dawson B, Horobin G, Illsley R, Mitchell R. A survey of childhood asthma in Aberdeen. Lancet 1969;i:827-30.

6 Clough JB, Hutchinson SA, Williams JD, Holgate ST Airway response to exercise and metacholine in children with respiratory symptoms. Arch Dis Child 1991;66: 579-83.

7 Sears MR, Jones DT, Holadaway MD. Prevelene of bronchial reactivity to inhaled metacholine in New Zealand schoolchildren. Thorax 1986;46:283-9.

8 Jackson AA, Wootton SA, Murphy JL. Nutrition and growth in childhood: gastrointestinal function. In: David TJ, ed. Recent advances in paediatrics. Vol 10. Edinburgh 991:111-28.

9 Tanner J, Whitehouse R. Clinical longitudinal standards for height, weight, height velocity, weight velocity and stages of puberty. Arch Dis Child 1976;51:170-9.

10 Marr JW. Individual dietary surveys: purposes of methods World Rev Nutr Diet 1971;13:105-64.

11 Paul AA, Southgate DAT. McCance and Widdowson's the composition of foods. London: HMSO, 1978.

12 Department of Health and Social Security. Recommended daily amounts of food eneroy and nutrients for groups of people in the United Kingdom. health and social subjects No 15.)

13 Jequier E. Measurement of energy expenditure in clinica nutritional assessment. Foumal of Parenteral and Enteral nutritional assessment. Foum
14 Schofield WN. Predicting basal metabolic rate, new standards and review of previous work. Human Nutrition: Clinical Nutrition 1985;39C(suppl 1):5-41.

15 Coles JT. A method for assessing age standardized weight for height in children seen cross-sectionally. Ann Hum Biol 1979;6:249-68.

16 Tanner JM, Whitehouse RH, Takaishi M. Standards from birth to maturity for height, weight, height velocity, and birth to maturity for height, weight, height velocity, and weight velocity: British

17 Brook CGD. Determination of body composition of children from skinfold measurements. Arch Dis Child 1971;46: $182-4$

18 Siri WE. The gross composition of the body. Advances in biology and medical physics. Vol 4. New York: Academic Press, 1956:239-80.

19 Spock A. Growth patterns in 200 children with bronchial asthma. Ann Allergy 1965;23:608-15.

20 Balfour-Lynn L. Growth and childhood asthma. Arch Dis Child 1986;61:1049-55.

21 Preece MA, Law CM, Davies PSW. The growth of children with chronic paediatric disease. Clinics in Endocrinology and Metabolism 1986;15:453-77.

22 Wolthers $\mathrm{O}$, Pedersen $\mathrm{S}$. Growth of asthmatic children during treatment with budesonide: a double blind trial. $B M F$ 1991;303:163-5.

23 Godfrey S, Balfour-Lynn L, Tooley M. A three- to five- year follow-up of the use of the aerosol steroid, beclomethasone dipropionate, in childhood asthma. $\mathcal{F}$ Allergy Clin Immunol 1978;62:335-9.

24 Cogswell J, El-Dishti $M$. Growth retardation in asthma: role of calorie deficiency. Arch Dis Child 1982;57:473-5.

25 Goldstein S, Ashkanazi J, Weissman C, Thomasow B, Kinney JM. Energy expenditure in patients with chronic obstructive pulmonary disease. Chest 1987;91:222-6.

26 Bartlett RG, Bruchach HF, Specht H. Oxygen cost of breathing. F Appl Physiol 1958;12:413-24.

27 Dukanovic R, Roche W, Wilson JW, et al. Mucosal inflammation in asthma. Am Rev Respir Dis 1990;142:434-57.

28 Vaisman N, Levy L, Pencharz P, et al. Effect of salbutomo on resting energy expenditure in patients with cystic on resting energy expenditure
fibrosis. $\mathcal{F}$ Pediatr 1987;111:137-9. 